Table 1. BASDAl and mental health (GHQ-12)- impact on daily activities ( $\mathrm{N}=542)$

\begin{tabular}{|c|c|c|c|c|c|c|}
\hline & \multicolumn{3}{|c|}{$\begin{array}{c}\text { BASDAI } \\
\text { Mean } \pm \text { SD }\end{array}$} & \multicolumn{3}{|c|}{$\begin{array}{c}\text { GHQ-12 } \\
\text { Mean } \pm \text { SD }\end{array}$} \\
\hline & $\begin{array}{l}\text { Low } \\
\text { limitation }\end{array}$ & $\begin{array}{c}\text { Medium } \\
\text { + High } \\
\text { Limitation }\end{array}$ & p-value & $\begin{array}{c}\text { Low } \\
\text { limitation }\end{array}$ & $\begin{array}{c}\text { Medium } \\
\text { + High } \\
\text { Limitation }\end{array}$ & p-value \\
\hline $\begin{array}{l}\text { Using public } \\
\text { transportation }\end{array}$ & $5.6 \pm 1.9$ & $6.1 \pm 1.9$ & .180 & $4.4 \pm 4.0$ & $5.3 \pm 4.0$ & .155 \\
\hline Driving & $5.5 \pm 2.0$ & $6.1 \pm 2.1$ & $.021^{*}$ & $4.2 \pm 3.9$ & $5.3 \pm 4.2$ & .050 \\
\hline $\begin{array}{l}\text { Doing physical } \\
\text { exercise }\end{array}$ & $4.7 \pm 2.1$ & $5.8 \pm 1.9$ & $<.001^{*}$ & $3.4 \pm 3.7$ & $4.7 \pm 4.0$ & $.002^{\star}$ \\
\hline $\begin{array}{l}\text { Engaging in inti- } \\
\text { mate relations }\end{array}$ & $5.2 \pm 1.9$ & $6.0 \pm 1.9$ & $<.001$ & $4.0 \pm 3.8$ & $5.1 \pm 4.0$ & $.015^{\star}$ \\
\hline $\begin{array}{l}\text { Caring for children / } \\
\text { grandchildren }\end{array}$ & $5.2 \pm 1.9$ & $6.0 \pm 2.0$ & .003 & $3.7 \pm 3.8$ & $5.2 \pm 4.1$ & .005 \\
\hline
\end{tabular}

${ }^{*} \mathrm{p} \leq .05$

Results: 542 axSpA patients participated. Mean age was $44.3 \pm 13.9$ years and $63 \%$ were female. Mean BASDAI was $5.3 \pm 2.1$, mean GHQ-12 score was $4.0 \pm 3.8$ and $50 \%$ were on biologics. $94 \%$ reported $\geq 1$ limitation in daily activities, of which physical exercise $(30 \%)$, house cleaning $(22 \%)$, intimacy $(21 \%)$ and stair climbing (21\%) were most commonly severely impacted (high limitation). Women reported significantly higher limitations in house cleaning, stair climbing, driving, moving around the house and caring for young children ( $p<.05$ for all activities vs men). Compared with low limitation, medium-high limitation in most activities was significantly associated with higher disease activity and worsened mental health for the overall population (Table 1).

Conclusion: Canadian axSpA patients, particularly women, are limited in daily life activities beyond those captured by other validated scales. Strong association between functional limitation, disease activity and mental health emphasizes the need for holistic evaluation of axSpA patients.

Disclosure of Interests: Proton Rahman Grant/research support from: Janssen and Novartis, Consultant of: Abbott, AbbVie, Amgen, BMS, Celgene, Lilly, Janssen, Novartis, and Pfizer., Speakers bureau: Abbott, AbbVie, Amgen, BMS, Celgene, Lilly, Janssen, Novartis, Pfizer, Marco Garrido-Cumbrera: None declared, Sherry Rohekar: None declared, Michael Mallinson: None declared, Gerald Major: None declared, Algis Jovaisas: None declared, Nigil Haroon: None declared, Wendy Gerhart: None declared, Artur J. deBrum Fernandes: None declared, Martin Cohen: None declared, Jon Chan: None declared, Patrick Leclerc Employee of: Novartis, Julie Schneiderman Employee of: Novartis, Robert Inman: None declared DOI: 10.1136/annrheumdis-2020-eular.4574

\section{SAT0639-HPR HOW DO PEOPLE WITH AXSPA PERCEIVE THE IMPACT OF DISEASE AND PHYSICAL ACTIVITY?}

A. K. Rausch Osthoff ${ }^{1}{ }^{2}$, S. Buechi ${ }^{3}$, T. P. M. Vliet Vlieland ${ }^{2}$, K. Niedermann Schneider ${ }^{1} .{ }^{1}$ Zurich University of Applied Sciences, Institute for Physiotherapy, Health, Winterthur, Switzerland; ${ }^{2}$ Leiden University Medical Center, Department of Orthopaedics, Rehabilitation and Physical Therapy, Leiden, Netherlands; ${ }^{3}$ Clinic Hohenegg, Clinic for Psychotherapy and Psychosomatics, Meilen, Switzerland

Background: The Ankylosing Spondylitis Association of Switzerland (SVMB) offers weekly group exercise therapy for people with axial Spondyloarthritis (axSpA) supervised by physiotherapists (PTs). Given the EULAR physical activity (PA) recommendations [1] and recent research [2, 3], the SVMB has implemented a new concept including assessments evaluating all fitness dimensions, daily PA and disease activity. Based on its results, individual exercise-coaching by the group PT is provided to support the adherence to exercising in correct mode and dose. PTs use the visual-tactile instrument PRISM (Pictorial Representation of IIIness and Self Measure) [5] to explore patients' perceived burden of disease (BD) and importance of PA as starting-point for the exercise-coaching. Objectives: To measure to what extent the perceived BD and importance of PA, measured with PRISM, change over time and to evaluate if the PRISM results are associated with established measures of disease activity and daily PA across four pilot groups including four PTs and 30 people with axSpA.

Methods: Each participant had three exercise-coaching sessions within six months. Each session was started by applying the PRISM, which is a white A4 board with a yellow disk at the bottom right hand corner. The participant was asked to imagine that the board represented his/her life and the yellow disk represented his/her "Self". Then, a red disk, representing axSpA, and later a blue disk, representing PA, were handed and the participant was asked to place the disks where they represented best their importance in the participant's life. The distances between Self and the red and blue disk respectively were measured in centimeters to quantify $\mathrm{BD} /$ importance of $\mathrm{PA}$, and correlated with the Bath Ankylosing Spondylitis Disease Activity Inventory, BASDAI (measuring disease activity) and weekly METs (measured with the International PA Questionnaire, IPAQ) by means of spearman rank correlation. The analysis was based on the first session at baseline (T0) and the third session after six months (T1) and paired t-test was applied, to identify changes between sessions.

Results: Complete data were available for 23 participants. Neither BD (distance to Self at T0: $13.7 \pm 7.2 \mathrm{~cm} ; \mathrm{T} 1: 12.1 \pm 6.2 \mathrm{~cm} ; \mathrm{t}=0.386, \mathrm{p}=0.703$ ) nor importance of PA (distance to Self at, T0: $7.3 \pm 5.3 \mathrm{~cm} ; \mathrm{T} 1: 7.0 \pm 4.5 \mathrm{~cm}$ ); $\mathrm{t}=0.246, \mathrm{p}=0.808$ ) changed within six months. The perceived importance of PA correlated with IPAQ measured METs at $\mathrm{T} 1$ ( $r=0.572, p=0.00)$, no correlation between BD and METs was found. Conclusion: The stable perceived BD could be explained by long disease duration of participants and established disease management. The stable importance of PA could be due to the sample, as for group exercise participants PA may already be important. The correlation between importance of PA and MET at T1 could indicate that people learned more about the meaning of PA leading to a better understanding of the importance of PA. Future research should evaluate factors influencing the perceived importance of PA as well as further explore the use of PRISM in the context of exercise-coaching.

\section{References:}

[1] Rausch AK, et al. Ann Rheum Dis 2018; 9(77):1251-1260. 45

[2] Sveaas SH, et al. Br J Sports Med 2019;0:1-7.

[3] Rausch AK, et al. RMD open, 2018; 4:e000713.

[4] Garber CE, et al. Med Sci Sports Exerc 2011;43:1334-59.

[5] Buchi S, et al. Psychother Psychosom 2002;71(6):333-341.

Acknowledgments: We thank Beatrice Walker and René Braem from Swiss Ankylosing Spondylitis Association.

Disclosure of Interests: None declared

DOI: 10.1136/annrheumdis-2020-eular.5385

\section{SAT0640-HPR RHEUMATOLOGY CARE OF MIGRANTS FROM SUB- SAHARAN AFRICA; A QUALITATIVE PILOT STUDY OF PATIENTS' PERSPECTIVES}

Z. Rutter-Locher ${ }^{1}$, J. Galloway ${ }^{2}$, H. Lempp ${ }^{2} .{ }^{1}$ Guy's and St Thomas' NHS Foundation Trust, Rheumatology Department, London, United Kingdom; ${ }^{2}$ King's College London, Centre for Rheumatic Diseases, London, United Kingdom

Background: Rheumatological diseases are common in Sub-Saharan Africa [1] but specialist healthcare is limited and there are less than 150 rheumatologists currently serving 1 billion people in Sub-Saharan Africa [2]. Rheumatologists practising in the UK NHS are likely to be exposed to migrant patients. There is therefore, an unmet need for health care providers to understand the differences in rheumatology healthcare provision between Sub-Saharan Africa and the UK and the barriers which migrants face in their transition of rheumatology care.

Objectives: To gain an understanding of the experiences of patients with rheumatological conditions, about their past healthcare in Sub-Saharan Africa and their transition of care to the UK.

Methods: A qualitative study using semi-structured interviews was conducted. Participants were recruited from two rheumatology outpatient clinics in London. Thematic analysis was applied to identify key themes.

Results: Seven participants were recruited. Five had rheumatoid arthritis, one had ankylosing spondylitis and one had undifferentiated inflammatory arthritis. Participants described the significant impact their rheumatological conditions had on their physical and emotional wellbeing, including their social and financial implications. Compared to the UK, rheumatology healthcare in Sub-Saharan Africa was characterised by higher costs, limited access to specialists, lack of investigations and treatments, the use of traditional medicines and poor communication by clinicians. Barriers to transition of rheumatology care to the UK were: poor understanding of rheumatological conditions by the public and primary care providers, lack of understanding of NHS entitlements by migrants, fear of data sharing with immigration services and delayed referral to specialist care. Patient, doctor and public education were identified by participants as important ways to improve access to healthcare. Conclusion: This study has described, for the first time, patients' perspectives of rheumatology health care in Sub-Saharan Africa and the transition of their care to the UK. These initial findings allow healthcare providers in the UK to tailor management for this migrant population and suggests that migrants need more information about their NHS entitlements and specific explanations on what non-clinical data will be shared with immigration services. To increase access to appropriate care, a concerted effort by clinicians and public health authorities is necessary to raise awareness and provide better education to patients and migrant populations about rheumatological conditions.

References:

[1] G. Mody, "Rheumatology in Africa-challenges and opportunities,"Arthritis Res. Ther., vol. 19, no. 1, p. 49, 2017.

[2] M. A. M. Elagib et al., "Sudan and Sweden Active Rheumatoid Arthritis in Central Africa: A Comparative Study Between," J. Rheumatol. J. Rheumatol. January, vol. 43, no. 10, pp. 1777-1786, 2016.

Acknowledgments: We are grateful to the patients involved in this study for their time and involvement.

Disclosure of Interests: None declared

DOI: 10.1136/annrheumdis-2020-eular.2789 